Yüzüncü Y1l Üniversitesi
Tarim Bilimleri Dergisi

Araştırma Makalesi (Research Article)

\title{
Şanlıurfa'da Yetiştirilen Bazı Nar (Punica granatum L.) Çeşitlerinin Fenolik Bileşenleri ve Antioksidan Aktivitelerinin Belirlenmesi**
}

\author{
Ali İKINCI' ${ }^{* 1}$, Emine DURSUN $^{2}$, Eyyüp KARAOĞUL ${ }^{3}$ \\ ${ }^{1}$ Harran Üniversitesi, Ziraat Fakültesi, Bahçe Bitkileri Bölümü, Şanlıurfa, Türkiye \\ ${ }^{2}$ Harran Üniversitesi, Fen Bilimleri Enstitüsü, Bahçe Bitkileri Anabilim Dalı, Şanlıurfa, Türkiye \\ ${ }^{3}$ Harran Üniversitesi, Mühendislik Fakültesi, Gıda Mühendisliği Bölümü, Şanlıurfa, Türkiye \\ ${ }^{1}$ https://orcid.org/0000-0001-8149-7095 ${ }^{2}$ https://orcid.org/0000-0001-5627-5140 ${ }^{3}$ https://orcid.org/0000-0001-8162-6838 \\ *Sorumlu yazar e-mail: aliikinci@harran.edu.tr
}

\section{Makale Bilgileri}

Geliș: 02.05.2021

Kabul: 12.07.2021

Online Yayınlanma 15.09.2021

DOI: $10.29133 /$ yyutbd.913208

\section{Anahtar Kelimeler}

Antioksidan aktivite,

Antosiyanin

Flavonoid,

Nar
Öz: Bu araştırmada Şanlıurfa'nın Merkez, Bozova, Harran ve Suruç ilçelerinden temin edilen Hicaznar, Katırbaşı, Devedişi, Suruç ve Suruç Karası nar çeşitlerinin meyve suyu ve çekirdeklerindeki toplam fenolik madde, toplam flavonoid, toplam antosiyanin miktarı ve antioksidan aktiviteleri incelenmiştir. Çalışma sonucunda; nar çeşitlerinden alınan meyve suyundaki toplam fenolik madde miktarının 26.60-40.43 $\mu \mathrm{g}$ GAE $\mathrm{g}^{-1}$ arasında, toplam flavonoid miktarının 572.66-1150.83 $\mu \mathrm{g} \mathrm{QE} \mathrm{g}{ }^{-1}$ arasında, toplam antioksidan kapasitenin \% 89.4796.38 arasında, toplam antosiyanin miktarının $0.84-24.12 \mathrm{mg}$ siyanidin 3-glikozit $1^{-1}$ arasında, çekirdeklerindeki toplam fenolik madde miktarının 95.39-146.44 $\mu \mathrm{g}$ GAE $\mathrm{g}^{-1}$ arasında, toplam flavonoid miktarının 983.57-1830.18 $\mu \mathrm{g}$ QE $\mathrm{g}^{-1}$ arasında, toplam antioksidan kapasitenin \% 7.76-26.64 arasında, toplam antosiyanin miktarının $0.19-3.51 \mathrm{mg}$ siyanidin 3-glikozit $\mathrm{l}^{-1}$ arasında olduğu tespit edilmiştir. Tüm çeşitler içinde en yüksek toplam fenolik madde miktarı ve toplam flavonoid miktarı çekirdek örneklerinde, toplam antioksidan kapasitesi ve toplam antosiyanin miktarı ise meyve suyu örneklerinde ölçülmüştür. Araştırmadan elde edilen sonuçlar ışığında, nar çeşitlerinin meyve suyu ve çekirdeklerinin zengin fitokimyasal içeriğe sahip olduğu ve insan sağlı̆̆ı üzerine faydalı fenolik bileşenleri yüksek miktarda içerdikleri görülmüştür.

\section{Determination of the Phenolic Contents and Antioxidant Activities of Some Pomegranate (Punica granatum L.) Cultivars Grown in Şanlıurfa}

\author{
Article Info \\ Received: 02.05.2021 \\ Accepted: 12.07.2021 \\ Keywords \\ Antioxidant activity, \\ Anthocyanin \\ Flavonoid, \\ Pomegranate.
}

Online Published 15.09.2021

DOI: 10.29133/yyutbd.913208

\begin{abstract}
In this research; total phenolic content, total flavonoid content, total anthocyanin content and antioxidant activities in fruit juices and seeds of Hicaznar, Katırbaşı, Devedişi, Suruç and Suruç Karası pomegranate cultivars obtained from the Central, Bozova, Harran and Suruç districts of Şanlıurfa were investigated. As a result of the study, the total amount of phenolic substance in the juice taken from pomegranate varieties is between 26.60-40.43 $\mu \mathrm{g} \mathrm{GAE} \mathrm{g}^{-1}$, the total amount of flavonoids is between $572.66-1150.83 \mu \mathrm{g} \mathrm{QE} \mathrm{g}{ }^{-1}$, the total antioxidant capacity is between $89.47-96.38 \%$, the total anthocyanin amount is between 0.84-24.12 mg cyanidin 3-glycoside $\mathrm{L}^{-1}$ between, the total amount of phenolic substance in the seeds is between 95.39-146.44 $\mu \mathrm{g} \mathrm{GAE} \mathrm{g}^{-1}$, the total amount of flavonoids is between 983.57-1830.18 $\mu \mathrm{g} \mathrm{QE} \mathrm{g}^{-1}$, the total antioxidant capacity is between $7.76-26.64 \%$, the total amount of anthocyanin is $0.19-3.51$ $\mathrm{mg}$ cyanidin 3-glycoside $\mathrm{L}^{-1}$ it was found to be between. The highest total
\end{abstract}


phenolic content and total flavonoid content among all cultivars were measured in seed samples, and total antioxidant capacity and total anthocyanin content in fruit juice samples. In the light of the results obtained from the research, it was seen that the juice and seeds of pomegranate varieties have rich phytochemical content and contain high amounts of phenolic components beneficial for human health.

${ }^{* *}$ Bu makale, Emine DURSUN'un "Bazı Nar (Punica granatum L.) Çeşitlerinin Pomolojik Özellikleri, Fenolik Bileşenleri ve Antioksidan Aktivitelerinin Belirlenmesi” başlıklı yüksek lisans tezinden üretilmiştir.

\section{Giriş}

Nar (Punica granatum L.), Punicaceae familyasına ait subtropik ve tropik iklim kuşağında yetiştirilen bir meyve türüdür. Eski çağların önemli meyve türlerinden birisi olan narın tarihçesinin günümüzden 7 bin yıl öncesine kadar uzandığı ifade edilmektedir. Mezopotamya'da M.Ö. 2500 yıllarına ait yazıtlarda, bu meyve türünden bahsedildiği bildirilmektedir (Kaygısız, 2009).

Nar potasyum, demir ve $\mathrm{C}$ vitamini bakımından zengin bir meyvedir. Narın çeşitli kısımlarından tanen, pektin, yağ, sitrik asit, sirke, hayvan yemi, boya, mürekkep ve çeşitli ilaç hammaddeleri elde edilmektedir (İkinci, 2007; Şimşek ve İkinci, 2017). Nar, taze olarak tüketilebildiği gibi meyve suyu, meyve suyu konsantresi, reçel, şarap ve liköre işlenebilen, çeşitli gıdalara renk verici ve tatlandırıcı olarak da kullanılabilmektedir. Nar içeriğindeki sağlık üzerine olumlu etkiler sağlayan bileşenler sayesinde uzun yıllardan beri halk arasında uygulanan geleneksel tedavi yöntemlerinde kullanılan bir meyvedir. Uzun yıllar süren bilimsel çalışmalar, narın insan vücudunu pozitif olarak etkileyen besin içerikleri ile yüklenmiş olduğunu ortaya çıkarmıştır (Şimşek ve İkinci, 2017).

Narın çeşitli ürünlere işlenmesinde önemli olan parametrelerin başında şeker, asitlik ve fenolik bileşikler gelmektedir. Vücutta serbest radikal oluşumunu önleyerek kanser ve kalp damar hastalıklarını önlemede bu fenolik bileşiklerin büyük bir etkisinin olduğu bildirilmektedir. Çeşitli çalışmalarda, antioksidan, bağışıklık artırıcı ve anti-kanserojenik özellikleri nedeniyle nar meyvesinin bitkisel bir tedavi edici olarak uygulanabileceği bildirilmiştir. Özütlerinde görülen benzersiz antimikrobiyal ve antioksidan etkileri nedeniyle bilim insanları narı kanser önleyici ajanlar olarak kullanma arayışına girmiştir (Gölükcü ve ark., 2011; Karimi ve Nowrozy, 2017).

Nar meyvesi temel olarak kabuk, çekirdek, tane ve beyaz zar olmak üzere 4 ana bölümden oluşmaktadır. Narın taneleri, meyvenin \% 52'sini oluşturmakta ve tanelerin ise \% 78'i meyve eti, \% 22 'si çekirdekten oluşmaktadır. Meyve suyu ise \% 84.5 oranında su ve buna ek olarak önemli miktarlarda suda çözünür kuru madde, fenolikler, antosiyaninler, askorbik asit, protein ve şeker içermektedir (Fadavi ve ark., 2005; Kulkarni ve Aradyha, 2005).

Narın suyunun yanı sıra çekirdeği ve kabuğunun da birçok fenolik bileşeni barındırdığı, bu bileşenlerin meyve suyuna önemli miktarda geçebildiği bildirilmiştir. Nar suyunun delfinidin, siyanidin, pelargonidin, ellajik asit, ellagatinler ve punikalajinden dolayı yüksek antioksidan kapasitesiye sahip olduğu bilinmektedir. Nar suyunda kumarik asit, klorojenik asit, ferulik asit, gallik asit, ellajik asit, protokateşik asit ve kafeik asit en çok bulunan fenolik asitlerdir. Nar çekirdeği önemli düzeyde palmitik asit, stearik, linoleik, linolenik ve oleik gibi yağ asitlerini, kabuk ise luteolin, kuersetin ve gallik asit gibi tanen flavonlarını içermektedir. Ayrıca; antimikrobiyal, antikanserojen, antiparasitik ve antiviral gibi özelliklere sahip olması nedeniyle, gelecek yıllarda bu meyveye olan ilginin daha da artacağı ifade edilmiştir (Singh ve ark., 2008; İlbey ve ark., 2009; Gündoğdu ve ark., 2010; Kelebek ve Canbaş, 2010; Nizamlığlu ve ark., 2010; Fischer ve ark., 2011; Karaca, 2011; Mizrahi ve ark., 2014; Ahmadiankia, 2019; Guerrero-Solano ve ark., 2020).

Nar meyvesinin kimyasal kompozisyonu yetiştirilme bölgesine, iklimine, çeşidine, dikim uygulamasına ve depolama koşullarındaki değişikliklere göre farklılık gösterir. Kimyasal kompozisyonuna bağlı olarak nar suları taze tüketim, sanayi üretimi veya tıbbi amaçlar için kullanılmaktadır. Yapılan çalışmalarda nar tanelerinde fizikokimyasal ve fonksiyonel parametreler açısından nar çeşitleri arasında önemli farklılıklar olduğu bulunmuştur. Nar; yüksek toplam polifenol içeriği, antioksidan aktivite, ham lif ve mineraller açısından da fonksiyonel gıda olarak kullanilabilmektedir (Martos ve ark., 2010; Marmol ve ark., 2017). 
$\mathrm{Bu}$ çalışmada, Şanlıurfa'da yaygın olarak yetiştirilen 'Hicaznar', 'Katırbaşı', 'Devedişi', 'Suruç' ve 'Suruç Karası' nar çeşitlerinin fizikokimyasal özelliklerinin ortaya konulması amaçlanmıştır. Araştırma kapsamında, nar çeşitlerine ait meyve suyu ve çekirdek örneklerinin toplam fenolik madde miktarı, toplam flavonoid miktarı, toplam antioksidan kapasitesi, toplam antosiyanin miktarı ve fenolik bileşik dağılımı belirlenmiş ve bu özellikleri karşılaştırılmıştır.

\section{Materyal ve Yöntem}

\subsection{Materyal}

Araştırma kapsamında materyal olarak, Şanlıurfa'nın Bozova ve Merkez ilçelerinden temin edilen Hicaznar, Harran ilçesinden temin edilen Hicaznar, Katırbaşı ve Devedişi, Suruç ilçesinden temin edilen Suruç ve Suruç Karası çeşitleri kullanılmıştır.

Nar meyveleri 10-21 Ekim 2018 tarihleri arasında hasat edilmiştir. Meyveler paslanmaz çelik bıçakla 2-4 parçaya ayrılarak, dane dokusuna zarar vermeyecek şekilde elle danelenmiştir. Meyve örneklerinden alınan 200'er gram dane örneklerinin katı meyve sıkacağ (Pro 120, Moulinex, Fransa) ile suyu çıkarılmış, çıkarılan sular kaba filtre kâğıdından geçirilmiş ve nar suyu örnekleri kimyasal analizler yapılıncaya kadar $-18^{\circ} \mathrm{C}$ 'de muhafaza edilmiştir. Daha sonra ayırılan çekirdek örneklerinin Soxhlet ekstraksiyon cihazı ile ekstraktları hazırlanmıştır.

\subsection{Yöntem}

\subsubsection{Fizikokimyasal analizler}

Araştırma kapsamında, Harran Üniversitesi Merkezi Laboratuvarı'nda meyve suyu ve çekirdek örneklerinin toplam fenolik madde miktarı, toplam flavonoid miktarı, toplam antioksidan kapasitesi ve toplam antosiyanin miktarı belirlenmiştir.

\subsubsection{Toplam fenolik madde miktarı}

Nar suyu örneklerinin toplam fenolik madde miktarı Singleton ve Rossi (1965) tarafindan geliştirilen metot esas alınarak gerçekleştirilmiştir. Bitkisel materyallerden alınan ekstraktlar, Folin \& Ciocalteau reaktifi 1:9 olacak şekilde saf su ile uygun oranlarda seyreltilmiştir. $0.4 \mathrm{ml}$ seyreltilen ekstrakt üzerine $0.1 \mathrm{~N} 2 \mathrm{ml}$ Folin-Ciocalteau ve $1.6 \mathrm{ml} \% 7.5 \mathrm{Na}_{2} \mathrm{CO}_{3}$ çözeltisi eklenip; vortekslenmiştir. Oda sıcaklığında 1 saat karanlık ortamda bekletilen karışımların, Shimadzu UV-1700 UV-Vis spektrofotometre ile $765 \mathrm{~nm}$ 'de absorbans değerleri okunmuştur. Toplam fenolik madde miktarı, standartlardan elde edilen kalibrasyon grafiği $\left(\mathrm{R}^{2}=0.99\right)$ yardımıyla hesaplanarak, sonuçlar $\mu \mathrm{g}$ GAE g ${ }^{-1}$ olarak verilmiştir.

\subsubsection{Toplam flavonoid miktarı}

Toplam flavonoid madde miktarı Zhinsen ve ark. (1999) tarafindan önerilen yöntemle belirlenmiştir. Nar suyu örneklerinin toplam flavonoid madde miktarı $\mu \mathrm{g} Q \mathrm{QE} \mathrm{g}^{-1}$ olarak spektrofotometrede [Shimadzu UV-1700 UV-Vis spektrofotometre, Japonya] absorbansin $510 \mathrm{~nm}$ 'de ölçülmesiyle tespit edilmiştir.

\subsubsection{Toplam antioksidan kapasitesi}

Antioksidan kapasitenin bir ifadesi olan DPPH radikalini indirgeme aktivitesi (antiradikal aktivite, \% ARA) Brand-Williams ve ark. (1995)'na göre belirlenmiştir. Analize başlanmadan önce DPPH radikali hazırlanmıştır. $0.008 \mathrm{~g}$ DPPH radikali amberli ve alüminyum ile kaplı şişeye alınmıştır. Üzerine $150 \mathrm{ml}$ çözücü (etanol) eklenmiştir. 1 gün karanlık ortamda çalkalanmış ve süre sonunda $50 \mathrm{ml}$ daha çözücü eklenmiştir. Daha sonra her bir bitkisel materyalin ekstraktları saf su ile $10 \mathrm{~kat}$ seyreltilmiştir. Ekstraktlardan $0.1,0.2$ ve $0.3 \mathrm{ml}$ alınarak, tüpler içerisine eklenmiştir. Her tüpe toplam $3 \mathrm{ml}$ olacak şekilde çözücü eklenmiştir. Üzerine $1 \mathrm{ml}$ DPPH radikali eklenerek, vorteks ile karıştırılıp, 
oda sıcaklığında karanlıkta 30 dakika bekletilmiştir. 30 dakika sonunda Shimadzu UV-1700 UV-Vis spektrofotometre ile $517 \mathrm{~nm}$ 'de absorbans değerleri okunmuştur. Ekstraktların antioksidan kapasitesinin bir ölçüsü olan \% ARA değerleri aşağıdaki formüle göre hesaplanmıştır (1).

$$
\% A R A=\left[A k-\left(\frac{\mathrm{Ak}}{\mathrm{Aö}}\right)\right] \times 100
$$

Ak: Kontrolün absorbans1

Aö: Örneğin absorbansı

\subsubsection{Toplam antosiyanin miktarı analizi}

Toplam antosiyanin miktarı içerikleri Giusti ve Wrolstad (2001) tarafından belirtilen pHdiferansiyel metoduna göre belirlenmiştir. $0.025 \mathrm{M} \mathrm{KCl}$ tamponu [pH 1.0] ve $0.4 \mathrm{M} \mathrm{CH}_{3} \mathrm{COONa}$ tamponu içerisinde inkubasyona tabi tutulan örneklerin absorbansları spektorfotometrede [Shimadzu UV-1700 UV-Vis spektrofotometre, Japonya] 520 ve $700 \mathrm{~nm}$ 'de ölçülmüş ve absorbans değerleri A [absorbans değeri $]=\left[\mathrm{A}_{520 \mathrm{~nm}}-\mathrm{A}_{700 \mathrm{~nm}}\right] \mathrm{pH} 1.0-\left[\mathrm{A}_{520 \mathrm{~nm}}-\mathrm{A}_{700 \mathrm{~nm}}\right] \mathrm{pH} 4.5$ formülüyle bulunmuştur. Örneklerin elde edilen absorbans değerleri aşağıda verilen eşitlik kullanılarak hesaplanmış ve toplam antosiyanin miktarı mg siyanidin 3-glikozit $100 \mathrm{ml}^{-1}$ olarak hesaplanmıştır (2).

Toplam antosiyanin miktar $=\left(\mathrm{A} * \mathrm{MW} \mathrm{DF}^{*} 10^{3}\right) / \varepsilon^{*} 1$

MW: Siyanidin-3-glikozidin molekül ağırlığı $=449.2 \mathrm{~g} \mathrm{~mol}^{-1}$

DF: Seyreltme faktörü

$\varepsilon$ : Siyanidin-3-glikozidin molar absorpsiyon katsay1s1 $=26.900$

\section{3. İstatiksel Analizler}

Araştırma, tesadüf parselleri deneme planında üç tekerrürlü ve her tekerrürde 5 meyve olacak şekilde yürütülmüştür. Analizlerinde, her örnek için iki paralel okuma yapılmıştır. İstatistiksel analizlerde elde edilen sonuçlar ortalama \pm standart sapma şeklinde ifade edilmiştir.

\section{Bulgular ve Tartışma}

\subsection{Toplam fenolik madde miktarı}

Şanlıurfa'da yaygın olarak yetiştirilen nar çeşitlerine ait meyve suyu ve çekirdek örneklerindeki toplam fenolik madde miktarları Çizelge 1 ile Şekil 1'de verilmiştir.

Araştırmada incelenen nar çeşitlerinin meyve sularında toplam fenolik madde miktarı 26.60$40.43 \mu \mathrm{g} \mathrm{GAE} \mathrm{g}^{-1}$ arasında değişim göstermiştir. Bozova ilçesinde yetiştirilen Hicaznar (Bozova) çeşidi en yüksek fenolik madde miktarı ile diğer örneklerden önemli düzeyde farklılık göstermiştir (Çizelge 1 ve Şekil 1). Nar çeşitlerinin çekirdeklerindeki toplam fenolik madde miktarı bakımından $146.44 \mu \mathrm{g}$ GAE $\mathrm{g}^{-1}$ ile Hicaznar (Merkez) en yüksek toplam fenolik madde miktarına sahip olduğu belirlenmiştir. Hicaznar (Merkez) çeşidini, Suruç Karası (133.60 $\mu \mathrm{g} \mathrm{GAE} \mathrm{g}^{-1}$ ) ve Hicaznar (Bozova) (131.25 $\mu \mathrm{g}$ GAE $\mathrm{g}^{-1}$ ) çeşitleri takip etmiştir (Çizelge 1 ve Şekil 1).

Yapılan analiz sonuçlarına göre nar çekirdeklerindeki toplam fenolik madde miktarının, meyve sularındaki miktardan daha yüksek olduğu saptanmıştır (Çizelge 1 ve Şekil 1). Özgen ve ark. (2008), ülkemizde yetiştirilen 6 nar çeşidine ait meyve suların toplam fenolik madde miktarının 1245-2076 mg $\mathrm{GAE}^{-1}$ arasında; Sarkhosh ve ark. (2009), İran'da yetiştirilen 21 farklı nar genotipine ait çekirdeklerin toplam fenolik madde miktarının 50.73-103.83 mg GAE $100 \mathrm{~g}^{-1}$ arasında; İzol (2012), Siirt'in Şirvan ilçesinde yetiştirilen bazı nar çeşit ve genotiplerinin danelerinde toplam fenolik madde miktarının 820.98-1303.60 mg GAE $~^{-1}$ arasında; Salgado ve ark. (2012), nar çekirdeğinin toplam fenolik madde

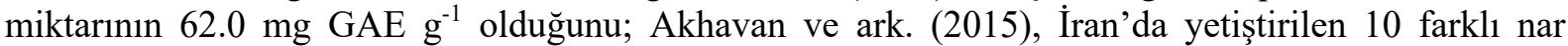
çeşidinde danelerden elde edilen ekstraktların toplam fenolik madde miktarının 220-1267 mg GAE ${ }^{-1}$ arasında, bütün meyvelerden elde edilen ekstraktların toplam fenolik madde miktarının 943-2931 mg

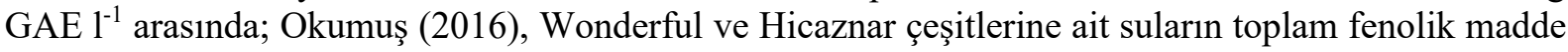


miktarının 1156.67-1428.1 mg GAE $^{-1}$ arasında, çekirdeklerin toplam fenolik madde miktarının 43.71$54.66 \mathrm{mg} \mathrm{GAE} \mathrm{g}^{-1}$ arasında; Ambigaipalan ve ark. (2017), toplam fenolik madde miktarının çekirdek ekstraktlarında (3.39 $\left.\mathrm{mg} \mathrm{GAE} \mathrm{g}^{-1}\right)$, meyve suyu ekstraktlarından (1.03 $\mathrm{mg} \mathrm{GAE} \mathrm{g}^{-1}$ ) yaklaşı üç kat fazla olduğunu; Özden (2018), Şanlıurfa' da yetiştirilen 3 nar çeşidinde toplam fenolik madde miktarının dane ekstraktlarında 728.88-906.66 mg GAE kg-1 arasında ve çekirdek ekstraktlarında 4733.33-6511.11 mg $\mathrm{GAE} \mathrm{kg}^{-1}$ arasında olduğunu bildirmişlerdir.

Çizelge 1. Nar çeşitlerinin meyve suyu ve çekirdek örneklerindeki toplam fenolik madde ve toplam flavonoid miktarı

\begin{tabular}{|c|c|c|c|c|}
\hline \multirow[b]{2}{*}{ Cessitler } & \multicolumn{2}{|c|}{$\begin{array}{l}\text { Toplam fenolik madde miktarı } \\
\qquad\left(\mu \mathrm{g} \mathrm{GAE} \mathrm{g}^{-1}\right)\end{array}$} & \multicolumn{2}{|c|}{$\begin{array}{l}\text { Toplam flavonoid miktarı } \\
\qquad\left(\mu \mathrm{g} \mathrm{QE} \mathrm{g}^{-1}\right)\end{array}$} \\
\hline & Meyve suyu & Çekirdek & Meyve suyu & Çekirdek \\
\hline Katırbaşı & $36.19 \pm 2.38$ & $119.97 \pm 4.08$ & $872.75 \pm 99.90$ & $1830.18 \pm 75.37$ \\
\hline Devedişi & $30.63 \pm 1.46$ & $125.94 \pm 1.91$ & $627.03 \pm 59.09$ & $1573.44 \pm 213.73$ \\
\hline Suruç & $28.61 \pm 3.57$ & $95.39 \pm 6.62$ & $572.66 \pm 44.15$ & $1040.01 \pm 6.19$ \\
\hline Suruç Karası & $29.89 \pm 4.73$ & $133.60 \pm 6.39$ & $868.62 \pm 28.68$ & $983.57 \pm 69.63$ \\
\hline Hicaznar (Merkez) & $26.60 \pm 2.42$ & $146.44 \pm 5.86$ & $1132.24 \pm 140.69$ & $1636.08 \pm 92.44$ \\
\hline Hicaznar (Bozova) & $40.43 \pm 0.77$ & $131.25 \pm 3.75$ & $1150.83 \pm 19.18$ & $1597.53 \pm 29.27$ \\
\hline Hicaznar (Harran) & $32.81 \pm 1.76$ & $100.21 \pm 3.31$ & $1026.93 \pm 56.37$ & $1161.84 \pm 51.37$ \\
\hline
\end{tabular}
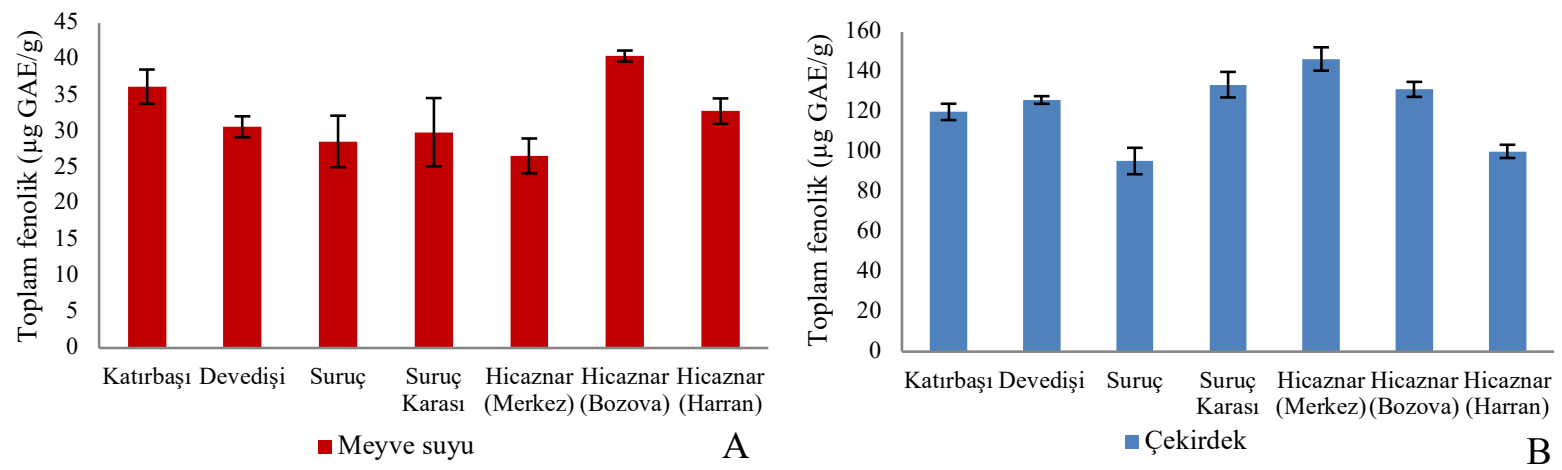

Şekil 1. Nar çeşitlerinin toplam fenolik madde miktarları (A: meyve suyu, B: çekirdek).

İncelenen nar çeşitlerinin meyve suyu ve çekirdek örneklerinin toplam fenolik madde miktarı, literatürdeki çalışmalarda da tespit edildiği gibi, meyve suyu örneklerinin toplam fenolik madde miktarından yaklaşık 3-4 kat daha yüksek olduğu saptanmıştır. Bu sonuç nar çekirdeğinin önemli bir gıda kaynağı olduğunu göstermektedir. Çalışmamızda elde edilen sonuçlar ile literatürdeki çalışma sonuçları kısmen benzerlik göstermektedir. Verilerdeki farklılıkların çeşit, olgunluk, yetişme bölgesi, presleme basıncı, örneklerin ekstrakte edildiği çözücü, kullanılan standart çözelti ve sonuçların farklı birimlerde değerlendirilmesi gibi nedenlerden kaynaklandığı düşünülmektedir.

\subsection{Toplam flavonoid miktarı}

Çeşitlere ait meyve suyu örneklerinin toplam flavonoid miktarları 572.66-1150.83 $\mu \mathrm{g} \mathrm{QE} \mathrm{g}^{-1}$ aralığında belirlenmiştir (Çizelge 1 ve Şekil 2). Toplam flavonoid miktarı bakımından Hicaznar (Bozova) çeşidini, Hicaznar (Merkez) (1132.24 $\mu \mathrm{g}$ QE g g ${ }^{-1}$ ve Hicaznar (Harran) (1026.93 $\mu \mathrm{g} \mathrm{QE} \mathrm{g}^{-1}$ ) çeşitleri izlemiştir. En düşük flavonoid miktarı ise $572.66 \mu \mathrm{g} \mathrm{QE} \mathrm{g}^{-1}$ ile Suruç çeşidinde tespit edilmiştir.

Çekirdek örneklerinin toplam flavonoid miktarı karşılaştırıldığında, en yüksek değer Katırbaşı çeşidinde $1830.18 \mu \mathrm{g} \mathrm{QE} \mathrm{g}{ }^{-1}$, en düşük değer ise Suruç Karası çeşidinde 983.57 $\mu \mathrm{g} \mathrm{QE} \mathrm{g}^{-1}$ olarak tespit edilmiştir (Çizelge 1 ve Şekil 2). Toplam flavonoid miktarı bakımından Katırbaşı çeşidini, Hicaznar (Merkez) (1636.08 $\mu \mathrm{g} \mathrm{QE} \mathrm{g}^{-1}$ ), Hicaznar (Bozova) (1597.53 $\mu \mathrm{g} \mathrm{QE} \mathrm{g}^{-1}$ ) ve Devedişi (1573.44 $\mu \mathrm{g}$ QE g$\left.{ }^{1}\right)$ çeşitleri takip etmiştir. Yapılan analiz sonuçlarına göre nar çekirdeklerindeki toplam flavonoid miktarının, meyve sularındaki miktardan daha yüksek olduğu saptanmıştır.

Karadeniz ve ark. (2005), nar suyunun toplam flavonoid miktarını $459 \mathrm{mg} \mathrm{QE} \mathrm{kg}{ }^{-1}$; Fawole ve ark. (2012), Güney Afrika'da yetiştirilen 3 nar çeşidinde toplam flavonoid miktarının 46.38-72.28 mg 
$100 \mathrm{ml}^{-1}$ arasında; Turgut ve Seydim (2013), bazı nar çeşit ve genotiplerinde toplam flavonoid miktarının 5.898-19.438 mg QE $100 \mathrm{ml}^{-1}$ arasında; Li ve ark. (2015), Çin'de yetiştirilen 10 nar çeşidinin dane ekstraktlarında toplam flavonoid miktarının 0.045-0.335 QE mg ml ${ }^{-1}$ arasında; Özden (2018), Şanlıurfa'da yetiştirilen 3 nar çeşidinde toplam flavonoid miktarının dane ekstraktlarında 458.33-559.21 mg QE kg-1, çekirdek ekstraktlarında 1677.63-3076.75 mg QE kg${ }^{-1}$ arasında olduğunu ve çekirdek ekstraktlarının toplam flavonoid miktarının, dane ekstraktlarından daha yüksek olduğunu bildirmişlerdir.

Çalışmamızda elde edilen bulgular, diğer araştırıcıların bulgularıyla kısmen örtüşmektedir. Özden (2018)'in çekirdek ekstraktlarının toplam flavonoid miktarının dane ekstraktlarından daha yüksek olduğu bulgusu, araştırma sonuçlarımız ile paralellik göstermektedir.
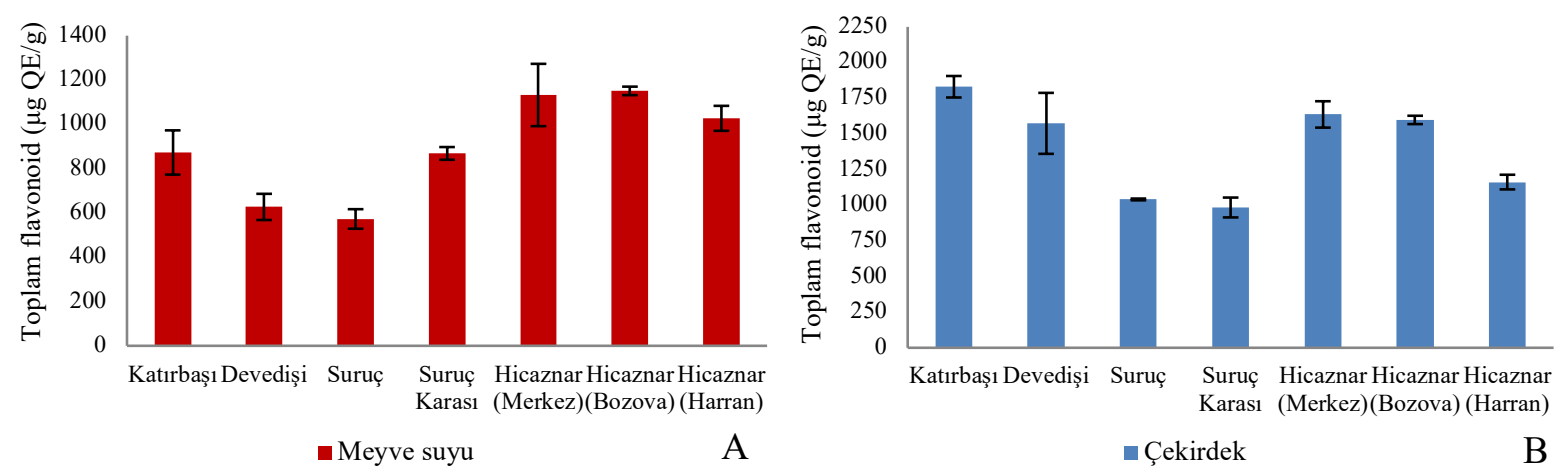

Şekil 2. Nar çeşitlerinin toplam flavonoid miktarları (A: meyve suyu, B: çekirdek).

\subsection{Toplam antioksidan kapasitesi}

Nar çeşitlerine ait meyve suyu ve çekirdek örneklerinde toplam antioksidan kapasiteleri Çizelge 2 ile Şekil 3’te verilmiştir.

Çizelge 2. Nar çeşitlerinin meyve suyu ve çekirdek örneklerindeki toplam antioksidan kapasite ve toplam antosiyanin miktarı

\begin{tabular}{lcccc}
\hline & \multicolumn{2}{c}{ Toplam antioksidan kapasite } & \multicolumn{2}{c}{$\begin{array}{c}\text { Toplam antosiyanin miktarı } \\
\text { (mg siyanidin 3-glikozit } ~^{-1} \text { ) }\end{array}$} \\
\cline { 2 - 5 } Çeşitler & Meyve suyu & Çekirdek & Meyve suyu & Çekirdek \\
\hline Katırbaş1 & $89.47 \pm 6.34$ & $12.68 \pm 3.67$ & $0.92 \pm 0.34$ & $0.71 \pm 0.64$ \\
Devedişi & $96.38 \pm 1.66$ & $15.03 \pm 5.85$ & $1.79 \pm 0.26$ & $1.18 \pm 0.64$ \\
Suruç & $96.10 \pm 1.28$ & $10.75 \pm 0.12$ & $0.84 \pm 0.74$ & $0.19 \pm 0.12$ \\
Suruç Karas1 & $94.96 \pm 2.35$ & $26.64 \pm 2.22$ & $1.02 \pm 0.42$ & $0.91 \pm 0.50$ \\
Hicaznar (Merkez) & $95.67 \pm 2.58$ & $10.32 \pm 2.84$ & $20.27 \pm 1.04$ & $2.58 \pm 2.25$ \\
Hicaznar (Bozova) & $94.53 \pm 1.60$ & $7.76 \pm 3.51$ & $24.12 \pm 1.73$ & $1.45 \pm 1.27$ \\
Hicaznar (Harran) & $92.39 \pm 2.68$ & $10.40 \pm 5.05$ & $14.62 \pm 1.03$ & $3.51 \pm 0.35$ \\
\hline
\end{tabular}
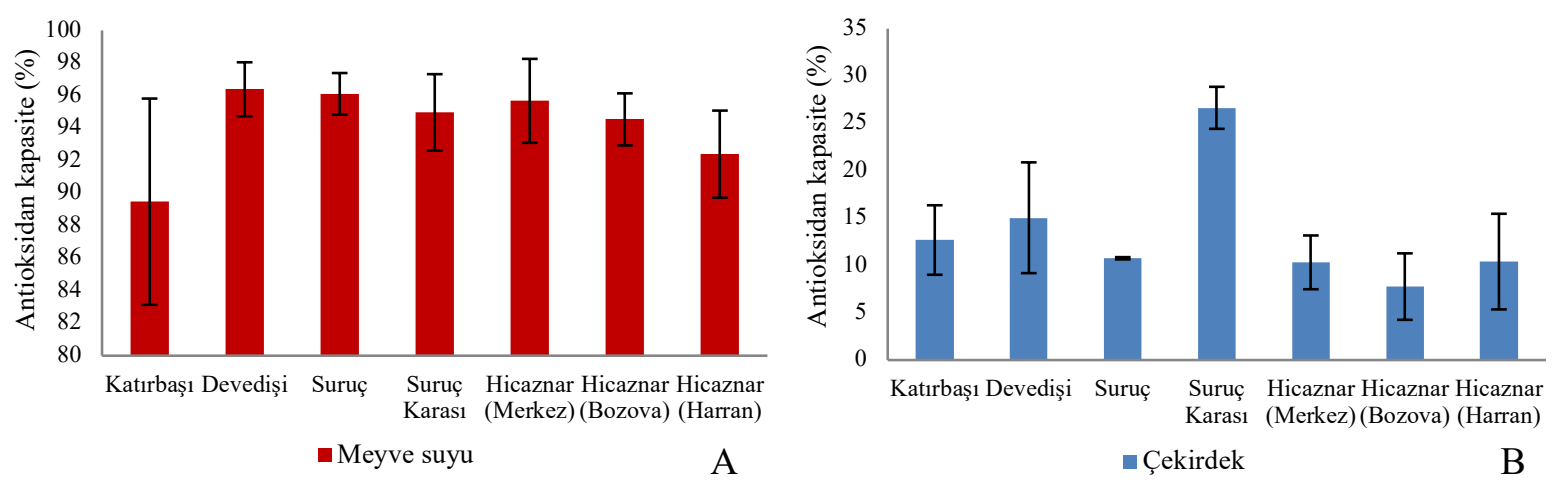

Şekil 3. Nar çeşitlerinin DPPH metodu ile antioksidan aktivite tayini (A: meyve suyu, B: çekirdek). 
Nar çeşitlerine ait meyve sularındaki toplam antioksidan kapasite bakımından en yüksek değer \% 96.38 ile Devedişi çeşidinde ve en düşük değer ise Katırbaşı çeşidinde \% 89.47 olarak tespit edilmiştir (Çizelge 2 ve Şekil 3). Toplam antioksidan kapasitesi bakımından Devedişi çeşidini, Suruç (\% 96.10) ve Hicaznar (Merkez) (\% 95.67) çeşitleri takip etmiştir.

Nar çeşitlerinin çekirdek örneklerindeki toplam antioksidan kapasite karşılaştırıldığında; en yüksek değer \% 26.64 ile Suruç Karası çeşidinde ve en düşük değer Hicaznar (Bozova) çeşidinde \% 7.76 olarak tespit edilmiştir (Çizelge 2 ve Şekil 3). Toplam antioksidan kapasitesi bakımından Suruç Karası çeşidini, Devedişi (\% 15.03) ve Katırbaşı (\% 12.68) çeşitleri izlemiştir.

Yapılan analiz sonuçlarına göre, tüm çeşitlerde en yüksek toplam antioksidan kapasite meyve suyu örneklerinde ölçülmüştür (Çizelge 2 ve Şekil 3). Surveswaran ve ark. (2007), nar çekirdeğinin antioksidan kapasitesini 3.53 mmol TE $100 \mathrm{~g}^{-1}$; Özgen ve ark. (2008), 6 farklı nar çeşidinin antioksidan kapasitesinin 0.56-0.770 mmol TE $100 \mathrm{ml}^{-1}$ arasında; Mousavinejad ve ark. (2009), İran' da yetiştirilen farklı çeşitlere ait nar sularının antioksidan kapasitesini DPPH metodu ile \% 18.60-42.80 arasında; Tezcan ve ark. (2009), ticari nar sularının antioksidan kapasitesini DPPH metodu ile \% 10.37-67.46 arasında; Tehranifar ve ark. (2010), İran'da yetiştirilen 20 nar çeşidinde antioksidan kapasitesini DPPH metodu ile \% 15.59-40.72 arasında; Karaca (2011), taze sıkılmış nar suyunda antioksidan kapasitesini DPPH metodu ile \% 79.6-86.2 arasında; Zaouay ve ark. (2012), Tunus'ta yetiştirilen 13 farklı çeşide ait nar sularının antioksidan kapasitesini DPPH metodu ile 9.57-21.07 mmol TE $^{-1}$ arasında; Turgut ve Seydim (2013), bazı nar çeşit ve genotiplerinin antioksidan kapasitesinin 1.004-1.641 mmol TE $100 \mathrm{ml}^{-}$ 1 arasında; Karaaslan ve ark. (2014), Türkiye'de yetiştirilen 4 farklı nar çeşidinin antioksidan kapasitesinin 267.3-381.2 mg TE $100 \mathrm{~g}^{-1}$ arasında; Kaur ve ark. (2014), Hindistan'da 6 farklı nar çeşidinin antioksidan kapasitesinin DPPH metodu ile 8.98-15.47 $\mu \mathrm{mol} \mathrm{TE} / \mathrm{g}$ arasında; Abbasoğlu (2016), Şanlıurfa'da 3 nar çeşidinin antioksidan kapasitesini DPPH metodu ile 4.70-19.42 mM TE $1^{-1}$ arasında; Okumuş (2016), Wonderful ve Hicaznar çeşitlerinin antioksidan kapasitesini DPPH metodu ile nar sularında 7.40-7.58 mmol TE ${ }^{-1}$, nar çekirdeklerinde 0.25-0.29 mmol TE g ${ }^{-1}$ arasında; Özden (2018), Şanlıurfa'da 3 nar çeşidinde dane ekstraktlarının toplam antioksidan kapasitelerinin, çekirdek ekstraktlarından daha yüksek olduğunu bildirmişlerdir.

Çalışmamızda meyve suyu örneklerinin toplam antioksidan kapasitelerinin, çekirdek örneklerinden daha yüksek olması literatür sonuçlarıyla uyumludur. Ayrıca araştırmamızda meyve suyu ve çekirdek örneklerinden elde edilen antioksidan kapasitesi değerlerinin, literatürde saptanan değerlerden daha yüksek olduğu da görülmüştür.

\subsection{Toplam antosiyanin miktarı}

Nar çeşitlerine ait meyve suyu ve çekirdek örneklerinde toplam antosiyanin miktarı Çizelge 2 ile Şekil 4'te verilmiştir. Araştırmada incelenen çeşitlerin meyve sularındaki toplam antosiyanin miktarı 0.84 (Suruç) mg siyanidin 3-glikozit $\mathrm{l}^{-1}$ ile $24.12 \mathrm{mg}$ siyanidin 3-glikozit $\mathrm{l}^{-1}$ (Hicaznar (Bozova)) arasında değişkenlik göstermiştir. Toplam antosiyanin miktarı bakımından Hicaznar (Bozova) çeşidini, Hicaznar (Merkez) (20.27 mg siyanidin 3-glikozit ${ }^{-1}$ ) ve Hicaznar (Harran) (14.62 mg siyanidin 3-glikozit l-1 $)$ çeşitleri takip etmiştir.

Çekirdek örneklerindeki toplam antosiyanin miktarı karşılaştırıldığında, en yüksek değer Hicaznar (Harran) çeşidinde $3.51 \mathrm{mg}$ siyanidin 3-glikozit l $^{-1}$ ve en düşük değer ise Suruç çeşidinde 0.19 mg siyanidin 3-glikozit $1^{-1}$ olarak tespit edilmiştir (Çizelge 2 ve Şekil 4). Toplam antosiyanin miktarı bakımından Hicaznar (Harran) çeşidini, Hicaznar (Merkez) (2.58 mg siyanidin 3-glikozit $1^{-1}$ ) ve Hicaznar (Bozova) (1.45 mg siyanidin 3-glikozit ${ }^{-1}$ ) çeşitleri izlemiştir. Analiz sonuçlarına göre, tüm çeşitlerde en yüksek toplam antosiyanin miktarı meyve suyu örneklerinde ölçülmüştür (Çizelge 2 ve Şekil 4).

Nar çeşit ve genotiplerinde toplam antosiyanin miktarının tespit edildiği diğer çalışmalar incelendiğinde; Özgen ve ark. (2008), Akdeniz Bölgesi’nde yetiştirilen 6 farklı nar çeşidinde toplam antosiyanin miktarının 0.61-21.9 mg $100 \mathrm{ml}^{-1}$ arasında; Çam ve ark. (2009), ülkemizde yetiştirilen 10 farklı nar çeşidinde toplam antosiyanin miktarının 8.1-36.9 mg $100 \mathrm{ml}^{-1}$ arasında; Tehranifar ve ark. (2010), İran'da yetiştirilen 20 farklı nar çeşidinde toplam antosiyanin miktarının 5.56-30.11 mg $100 \mathrm{~g} \mathrm{~g}^{-1}$ arasında; Sepulveda ve ark. (2010), Şili'de yetiştirilen 8 nar genotipinde toplam antosiyanin miktarının 16.8-132.8 mg siyanidin 3-glikozit $100 \mathrm{ml}^{-1}$ arasında; İzol (2012), Siirt'in Şirvan ilçesinde yetiştirilen bazı nar çeşit ve genotiplerinin danelerinde toplam antosiyanin miktarının 27.16-171.86 mg siyanidin 
3-glikozit kg ${ }^{-1}$ arasında; Fawole ve ark. (2012), Güney Afrika'da yetiştirilen 3 nar çeşidinde toplam antosiyanin miktarının 16.53-26.93 mg $100 \mathrm{ml}^{-1}$ arasında; Turgut ve Seydim (2013), bazı nar çeşit ve genotiplerinde toplam antosiyanin miktarının 9.892-34.616 mg siyanidin 3-glikozit $100 \mathrm{ml}^{-1}$ arasında; Abbasoğlu (2016), Şanlıurfa'da 3 nar çeşidinde toplam antosiyanin miktarının 2.07-67.84 mg siyanidin 3-glikozit $1^{-1}$ arasında; Okatan ve ark. (2018), Bitlis'in merkez bölgesinde yetişen nar genotiplerinde toplam antosiyanin miktarının 55.37-156.03 mg siyanidin 3-glikozit $1^{-1}$ arasında; Özden (2018), Şanlıurfa' da 3 nar çeşidinde toplam antosiyanin miktarının nar danelerinde 46.58-347 mg siyanidin 3glikozit $\mathrm{kg}^{-1}$, nar çekirdeklerinde 54.93-68.29 mg siyanidin 3-glikozit $\mathrm{kg}^{-1}$ arasında; Özkan ve ark. (2018), Zivzik narında toplam antosiyanin miktarının 16.3-21.7 mg siyanidin-3-glikozit $100 \mathrm{~g}^{-1}$ arasında değişiklik gösterdiğini bildirmişlerdir.

Toplam antosiyanin miktarı açısından elde etmiş olduğumuz değerler, diğer araştırıcıların bulgularıyla kısmen uyumlu bulunmaktadır. Dane renkleri pembe ve açık pembe olan Devedişi, Katırbaşı, Suruç ve Suruç Karası çeşitlerinin meyve suyu ve çekirdek örneklerinin toplam antosiyanin miktarı, dane rengi kırmızı olan Hicaznar çeşitlerinden daha düşük saptanmıştır.
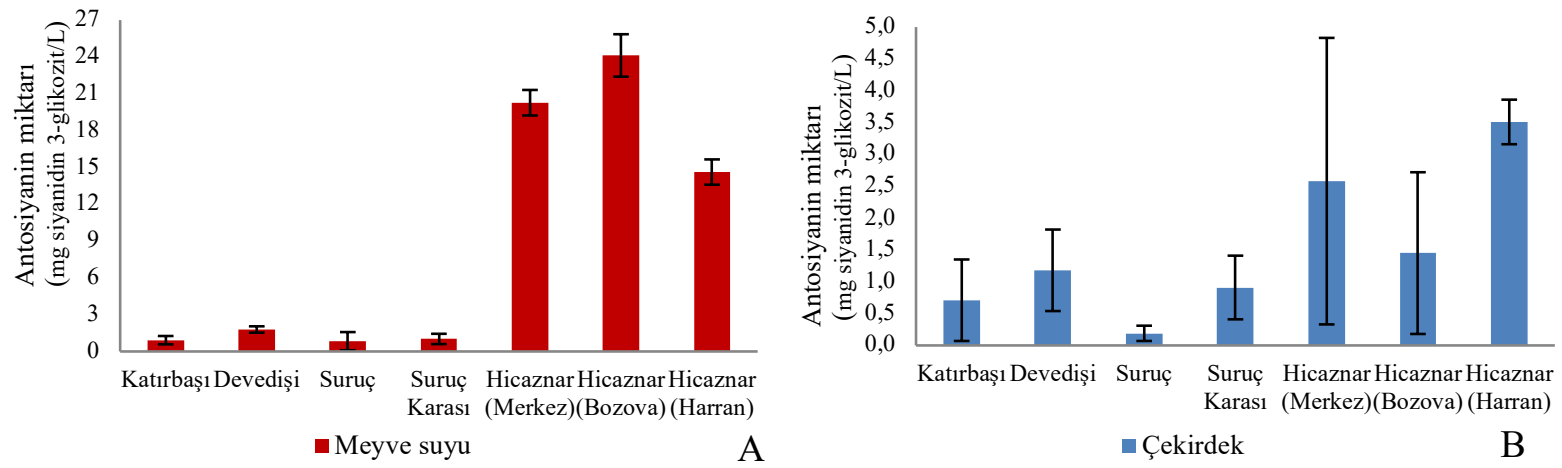

Şekil 4. Nar çeşitlerinin toplam antosiyanin miktarı (A: meyve suyu, B: çekirdek).

\section{Sonuç}

Araştırma sonucunda; çalışmada kullanılan nar çeşitlerinden alınan meyve örneklerinin analiz edilmesi sonucunda hem çeşitlerin birbiri arasında hem de meyvelerden alınan meyve suyu ve çekirdek özlerinin birbiri ile kıyaslanması bakımından toplam fenolik madde miktarı, toplam flavonoid miktarı, toplam antioksidan kapasite ve toplam antosiyanin miktarları değişkenlik göstermiştir. Araştırmada incelenen tüm nar çeşitlerinde fenolik madde ve toplam flavonoid miktarının çekirdeklerde daha fazla olduğu, buna karşılık toplam antioksidan kapasitesi ve toplam antosiyanin miktarının ise meyve suyu örneklerinde daha yüksek düzeyde olduğu saptanmıştır.

Araştırmadan elde edilen sonuçlar 1şı̆̆ında, nar çeşitlerinin meyve suyu ve çekirdeklerinin toplam fenolik madde miktarı, toplam flavonoid miktarı, toplam antioksidan kapasitesi, toplam antosiyanin miktarı ve sağlık açısından faydalı fenolik bileşenleri yüksek miktarda içerdikleri görülmüştür. Sofralık tüketim ve meyve suyu endüstrisinde kullanımının yanında, özellikle albenisi olmayan ve bu yüzden yetiştiriciler tarafindan tercih edilmeyen Suruç Karası çeşidinin, çekirdeklerindeki oldukça yüksek fenolik madde ve antioksidan kapasite nedeniyle fonksiyonel ürün olarak da endüstriyel kullanımının yaygınlaştırılması önerilmektedir.

Nar yetiştiriciliği için uygun ekolojik koşullara sahip olan bölgemizde üreticilerin nar yetiştiriciliği konusunda bilinçlendirilmesi ve yetiştiriciliğinin yaygınlaştırılmasının bölge ve ülke ekonomisine de önemli bir katkı sağlayacağı düşünülmektedir.

\section{Teşekkür}

Bu çalışma, Harran Üniversitesi Bilimsel Araştırma Projeleri (BAP) Koordinatörlüğü tarafından 19033 nolu proje kapsamında desteklenmiştir. 


\section{Kaynakça}

Abbasoğlu, D. R. (2016). Şanlıurfa'da yetiştirilen bazı nar çeşitlerinin kimyasal ve biyokimyasal özellikleri. Yüksek Lisans Tezi, Harran Üniversitesi, Fen Bilimleri Enstitüsü, Şanlıurfa, 50s.

Ahmadiankia, N. (2019). Molecular targets of pomegranate (Punica granatum L.) in preventing cancer metastasis. Iran J. Basic Med. Sci., 22(9), 977-988.

Akhavan, H., Barzegar, M., Weidlich, H., \& Zimmermann, B. F. (2015). Phenolic compounds and antioxidant activity of juices from ten Iranian pomegranate cultivars depend on extraction. Journal of Chemistry, 1-7.

Ambigaipalan, P., Camargo, A. C., \& Shahidi, F. (2017). Identification of phenolic antioxidant and bioactives of pomegranate seeds following juice extraction using HPLC-DAD-ESI-MS. Food Chemistry, 221, 1883-1894.

Brand-Williams, W., Cuvelier, M. E., \& Berset, C. (1995). Use of a free radical method to evaluate antioxidant activity. Lwt - Food Science and Technology, 28(1), 25-30.

Cam, M., Hisil, Y., \& Durmaz, G. (2009). Classification of eight pomegranate juices based on antioxidant capacity measured by four methods. Food Chemistry, 112, 721-726.

Cemeroğlu, B. (2007). Gıda analizleri. Gıda Teknolojisi Derneği Yayınları, No: 34, Bizim Büro Basımevi, Kızılay, Ankara, 535s.

Fadavi, A., Barzegar, M., Azizi, M. H., \& Bayat, M. (2005). Physicochemical composition of ten pomegranate cultivars (Punica granatum L.) grown in Iran. International Food Science and Technology, 11(2), 113-119.

Fawole, O. A., Opara, U. L., \& Theron, I. K. (2012). Chemical and phytochemical properties and antioxidant activities of three pomegranate cultivars grown in South Africa. Food and Bioprocess Technology, 5(7), 2934-2940.

Fischer, U. A., Carle, R., \& Kammerer, D. R. (2011). Identification and quantification of phenolic compounds from pomegranate (Punica granatum L.) peel, mesocarp, aril and differently produced juices by HPLC-DAD-ESI/MSn. Food Chemistry, 127(2), 807-821.

Giusti, M. M., \& Wrolstad, R. E. (2001). Characterization and measurement of antocyanins by UVvisible spectroscopy. Current Protocols in Food Analytical Chemistry, John Wiley and Sons, Inc., Hoboken, F1.2.1.-F1.2.13.

Gölükcü, M., Tokgöz, H., \& Kıralan, M. (2008). Ülkemizde yetiştirilen önemli nar (Punica granatum L.) çeşitlerine ait çekirdeklerin bazı özellikleri. Glda, 33(6), 281-290.

Guerrero-Solano, J. A., Jaramillo-Morales, O. A., Velázquez-González, C., La O-Arciniega, D., Castañeda-Ovando, A., Betanzos-Cabrera, G., \& Bautista, M. (2020). Pomegranate as a potential alternative of pain management. A review. Plants, 9(4), 419.

Gündoğdu M. (2006). Pervari (Siirt) yöresi nar (Punica granatum L. ) populasyonlarında mahalli tiplerin seleksiyonu. Yüksek Lisans Tezi, Yüzüncü Yıl Üniversitesi, Fen Bilimleri Enstitüsü, Van.

Gündoğdu, M., Yılmaz, H., Şensoy, R. G., \& Gündoğdu, Ö. (2010). Şirvan (Siirt) yöresinde yetiştirilen narların pomolojik özellikleri. Yüzüncü Yıl Üniversitesi Tarım Bilimleri Dergisi, 20(2), 138143.

Ilbey, Y. O., Ozbek, E., Simsek, A., Cekmen, M., Somay, A., \& Tasci, A. I. (2009). Effects of pomegranate juice on hyperoxaluria-induced oxidative stress in the rat kidneys. Ren. Fail., $31(6), 522-531$.

İkinci, A. (2007). Nar yetiştiriciliği. Tarım Türk Dergisi, (7): 12-16.

İzol, G. (2012). Güneydoğu Anadolu Bölgesi'nde yetiştirilen Zivzik ve Görümlü narlarının fizikokimyasal özelliklerinin belirlenmesi. Yüksek Lisans Tezi, Harran Üniversitesi, Fen Bilimleri Enstitüsü, Şanlıurfa, 73s.

Karaaslan, M., Vardin, H., Varlıklız, S., \& Y1lmaz, F. M. (2014). Antiproliferative and antioxidant activities of Turkish pomegranate (Punica granatum L.) accessions. International Journal of Food Science and Technology, 49(1), 82-90.

Karaca, E. (2011). Nar suyu konsantresi üretiminde uygulanan bazı işlemlerin fenolik bileşenler üzerine etkisi. Yüksek Lisans Tezi, Çukurova Üniversitesi, Fen Bilimleri Enstitüsü, Adana, 157s.

Karadeniz, F., Burdurlu, H. S., Koca, N., \& Soyer, Y. (2005). Activity of selected fruits and vegetables grown in Turkey. Turkish Journal of Agricultural Foresty, 29, 297-303. 
Karimi, H. R., \& Nowrozy, M. (2017). Effects of rootstock and scion on graft success and vegetative parameters of pomegranate. Scientia Horticulturae, 214, 280-287.

Kaur, C., Pal, R. K., Kar, A., Gadi, C., Sen, S., Kumar, P., Chandra, R., Jaiswal, S., \& Khan, I. (2014). Characterization of antioxidants and hypoglycemic potential of pomegranate grown in India: A preliminary investigation. Journal of Food Biochemistry, 38, 397-406.

Kaygısız, H. (2009). Narın tarihçesi ve önem kazanmasının nedenleri. Hasad Dergisi, 24(2), 64-66.

Kelebek, H., \& Canbaş, A. (2010). Hicaz Narı şırasının organik asit şeker ve fenol bileşikleri içeriği ve antioksidan kapasitesi. Glda, 35(6), 439-444.

Kulkarni, A. P., \& Aradhya, S. M. (2005). Chemical changes and antioxidant activity pomegranate arils during fruit development. Food Chemistry, 93(2), 319-324.

Li, X., Wasila, H., Liu, L., Yuan, T., Gao, Z., Zhao, B., \& Ahmad, I. (2015). Physicochemical characteristics, polyphenol compositions and antioxidant potential of pomegranate juices from 10 Chinese cultivars and the environmental factors analysis. Food Chemistry, 175(15), 575-584.

Marmol, F. A., Jauregui, N. N., Sanchez, F. G., Martinez-Nicolas, J. J., \& Hernandez, F. (2017). Characterization of twenty pomegranate (Punica granatum L.) cultivars grown in Spain: aptitudes for fresh consumption and processing. Scientia Horticulturae, 219, 152-160.

Martos, M. V., Navajas, Y. R., Lopez, J. F., Sendra, E., Barbera, E. S., \& Alvarez, J. A. P. (2010). Pomegranate and its many functional components as related to human health: A review. Comprehensive Reviews in Food Science and Food Safety, 9, 635-654.

Mastrodi Salgado, J., Baroni Ferreira, T.R., de Oliveira Biazotto, F., \& Dos Santos Dias, C. T. (2012). Increased antioxidant content in juice enriched with dried extract of pomegranate (Punica granatum L.) peel. Plant Foods for Human Nutrition, 67(1), 39-43.

Mizrahi, M., Friedman-Levi, Y., Larush, L., Frid, K., Binyamin, O., Dori, D., Fainstein, N., Ovadia, H., Ben-Hur, T., Magdassi, S., \& Gabizon, R. (2014). Pomegranate seed oil nanoemulsions for the prevention and treatment of neurodegenerative diseases: The case of genetic CJD. Nanomedicine, 10(6), 1353-1363.

Mousavinejad, G., Emam-Djomeh, Z., Rezaei, K., \& Khodaparast, M. H. H. (2009). Identification and quantification of phenolic compounds and their effects on antioxidant activity in pomegranate juices of eight Iranian cultivars. Food Chemistry, 115, 1274-1278.

Nizamlığlu, N. M., \& Nas, S. (2010). Meyve ve sebzelerde bulunan fenolik bileşikler: Yapıları ve önemleri. Glda Teknolojileri Elektronik Dergisi, 5(1), 20-35.

Okatan, V., Colak, A. M., Guclu, S. F., \& Gundogdu, M. (2018). The comparison of antioxidant compounds and mineral content in some pomegranate (Punica granatum L.) genotypes grown in the east of Turkey. Acta Scientiarum Polonorum Hortorum Cultus, 17(4), 201-211.

Okumuş, G. (2016). Nar (Punica granatum L.) kabuk ve çekirdeklerinin antioksidan kapasitelerinin belirlenmesi. Yüksek Lisans Tezi, Uludağ Üniversitesi, Fen Bilimleri Enstitüsü, Bursa, 121s.

Ozgen, M., Durgac, C., Serce, S., \& Kaya, C. (2008). Chemical and antioxidant properties of pomegranate cultivars grown in Mediterranean region of Turkey. Food Chemistry, 111, 703706.

Ozkan, G., Fidan, H., Ercisl1, S., Stoyanova, A., Zeb, A., Hanina, H., Agar, G., Sagbas, H. I., \& Ilhan, G. (2018). Phenotypic and biochemical parameters within historical Zivzik pomegranate cultivar. Comptes Rendus de l'Acade'mie Bulgare des Sciences, 71(11), 1466-1472.

Özden, A. N., 2018. Bazı abiyotik elisitörlerin nar (Punica granatum L.) kallus kültüründe fenolik biyosentezi ve antioksidan kapasite üzerine etkilerinin araştırılması. Doktora Tezi, Harran Üniversitesi, Fen Bilimleri Enstitüsü, Şanlıurfa, 106s.

Sarkhosh, A., Zamani, Z., Fatahi, R., \& Ranjbar, H. (2009). Evaluation of genetic diversity among Iranian soft-seed pomegranate accessions by fruit characteristics and RAPD markers. Scientia Horticulturae, 121(3), 313-319.

Sepulveda, E., Saenz, C., Pena, A., Robert, P., Bartolome, B., \& Gomez-Cordoves, C. (2010). Influence of the genotype on the anthocyanin composition, antioxidant capacity and color of Chilean pomegranate (Punica granatum L.) juices. Agric. Res., 70, 50-57.

Singh, M., Arseneault, M., Sanderson, T., Morthy, V., \& Ramassamy, C. (2008). Challenges for research on polyphenols from foods in alzheimer's disease: bioavailability, metabolism and cellular and molecular mechanism. Journal of Agriculture and Food Chemistry, 56, 4855-4873. 
Singleton, V. L., \& Rossi, J. A. (1965). Colorimetry of total phenolics with phosphomolybdicphosphotungstic acid reagents. American Journal of Enology and Viticulture, 16, 144-153.

Surveswaran, S., Ca1, Y. Z., Corke, H., \& Sun, M. (2007). Systematic evaluation of natural phenolic antioxidants from 133 Indian medicinal plants. Food Chemistry, 102, 938-953.

Şimşek, M., \& İkinci, A. (2017). Narın (Punica granatum L.) insan sağlığına etkileri. Harran Tarım ve Glda Bilimleri Dergisi, 21(4), 494-506.

Tehranifar, A., Zarei, M., Nemati, Z., Esfendiyari, B., \& Vazifeshenas, M. R. (2010). Investigation of physico-chemical properties and antioxidant activity of twenty Iranian pomegranate (Punica granatum L.) cultivars. Scientia Horticulturae, 126, 180-185.

Tezcan, F., Gultekin, M. O., Diken, T., Ozcelik, B., \& Er, M. B. (2009). Antioxidant activity and total phenolic, organic acid and sugar content in commercial pomegranate juices. Food Chemistry, $115,873-878$.

Tibet, H., \& Onur, C. (1999). Antalya'da nar (Punica granatum L.) çeşit adaptasyonu (111). Türkiye 3. Ulusal Bahçe Bitkileri Kongresi. 14-17 Eylül 1999, Ankara.

Turgut, D. Y., \& Seydim, A. C. (2013). Akdeniz Bölgesi’nde yetiştirilen bazı (Punica granatum L.) çeşit ve genotiplerinin fenolik bileşenleri ve antioksidan aktivitelerinin belirlenmesi. Akademik Gida, 11(2), 51-59.

Zaouay, F., \& Mars, M. (2011). Diversity among Tunisian pomegranate (Punica granatum L.) cultivars as assessed by pomological and chemical traits. International Journal of Fruit Science, 11(2), 151-166.

Zhishen, J., Mengcheng, T., \& Jianming, W. (1999). The determination of flavonoid contents in mulberry and their scavenging effects on superoxide radicals. Food Chemistry, 64, 555-559. 